\title{
Types of the Dipterans of the Families Cypselosomatidae, Micropezidae, and Tethinidae (Diptera, Acalyptratae) in the Collection of the Zoological Institute of the Russian Academy of Sciences in St. Petersburg
}

\author{
E. P. Nartshuk ${ }^{a}$, , N. M. Paramonov ${ }^{a}$, and T. A. Suleymanova ${ }^{a}$ \\ a Zoological Institute, Russian Academy of Sciences, St. Petersburg, 199034 Russia \\ *e-mail:chlorops@zin.ru
}

Received May 20, 2021; revised June 3, 2021; accepted June 3, 2021

\begin{abstract}
A catalogue of the types (holotypes, paratypes, lectotypes, and paralectotypes) of the species of the families Cypselosomatidae, Micropezidae, and Tethinidae (Diptera, Acalyptratae) described by T. Becker, V.L. Beschovski, E.P. Nartshuk, A.L. Ozerov, A.I. Shatalkin, and Á. Soós, deposited in the collection of the Zoological Institute of the Russian Academy of Sciences in St. Petersburg, is presented. The lectotype of Calobata nigrolamellata Becker, 1907 is designated. Photographs of the specimens and their labels are given.
\end{abstract}

Keywords: Diptera, Cypselosomatidae, Micropezidae, Tethinidae, holotypes, paratypes, lectotypes, paralectotypes, Zoological Institute of the Russian Academy of Sciences

DOI: $10.1134 / \mathrm{S} 0013873821040072$

In the present paper, the type material of the dipterans belonging to three families of the Acalyptratae group, deposited in the collection of the Zoological Institute, Russian Academy of Sciences, St. Petersburg (ZISP), is described.

The photographs were taken with a Canon EOS 800D camera with a MP-E $65 \mathrm{~mm}$ objective and put together and processed by Helicon Focus 6 software.

Family CYPSELOSOMATIDAE Hendel, 1931

This very small family includes two genera from Eastern Asia and Australia. In Russia, one species is known from the Far East. The larvae of the Australian species develop in bat guano.

Tenuia smirnovi Shatalkin, 1994

Shatalkin, 1994 : 143 (Fig. 1).

Paratype: male, "Khabarovsk[ii] Terr.[,] Pashkovo, 17.VII.1980 (A. Ozerov)" (in Cyrillic). The inventory number is INS_DIP_0000901. A microvial with the genitalia is pinned under the specimen. The holotype and the other paratypes are deposited in the Zoological Museum of M.V. Lomonosov Moscow State University (MSU) in Moscow.

Family MICROPEZIDAE Desmarest, 1860

The flies vary from small to medium-sized (3.5$15 \mathrm{~mm}$ ), have a narrow body and long stilt-shaped legs. The family is world-wide distributed, but is most diverse in the tropical regions. Approximately 500 species of 40 genera are described in the World fauna, with up to 30 species of 5 genera known from Russia. Larvae of most of the species are saprophagous, those of Micropeza corrigiolata (Linnaeus, 1758) eat out the root nodules of Fabaceae.

Micropeza nitidicollis Becker, 1907

Becker, $1907: 293$.

Described from a single female with the label "Gashun Gobi im östl. Chines. Turkestan: Fl. Danche südlich von 


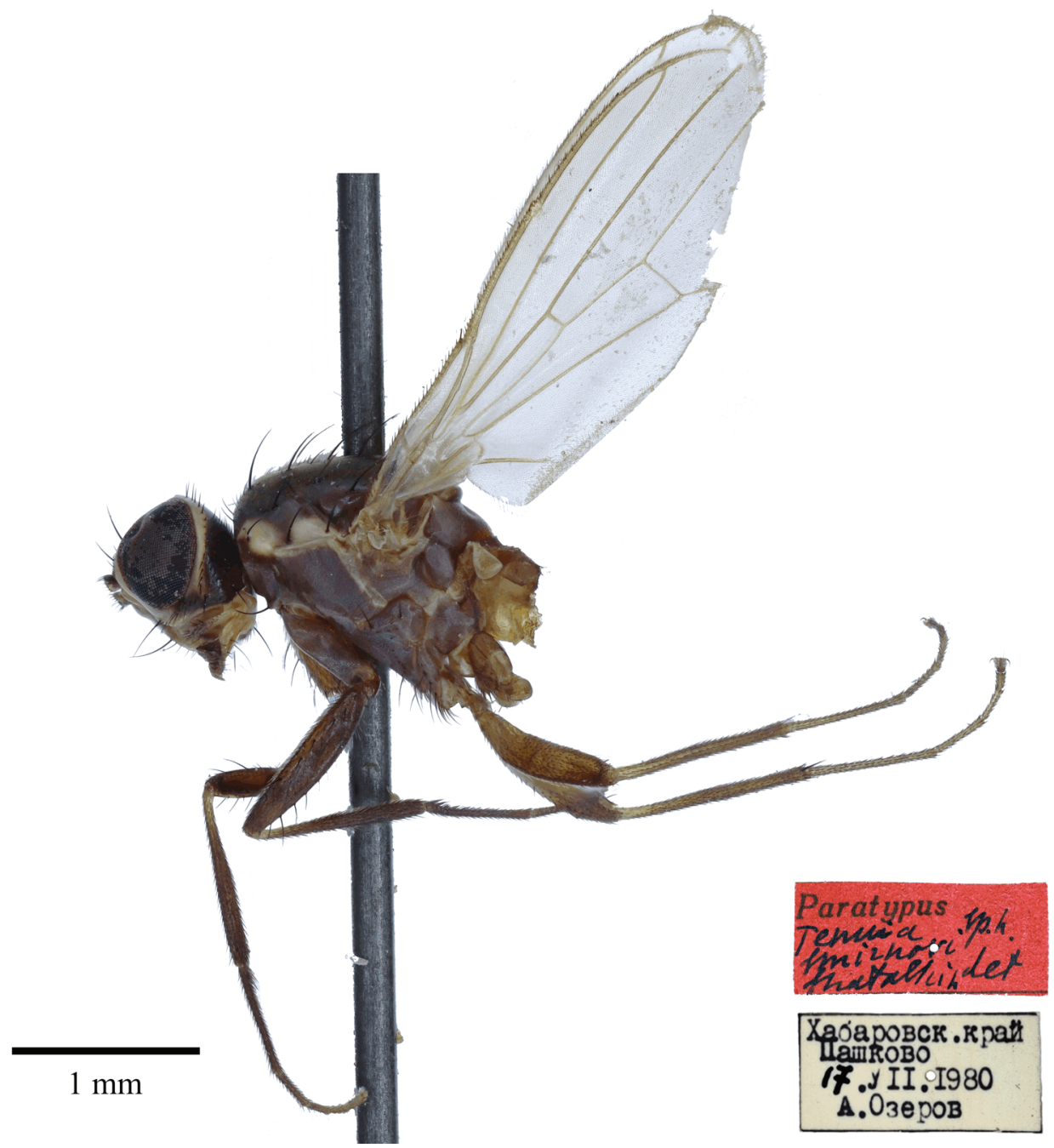

Fig. 1. Tenuia smirnovi Shatalkin, 1994, paratype. Photograph by N.M. Paramonov.

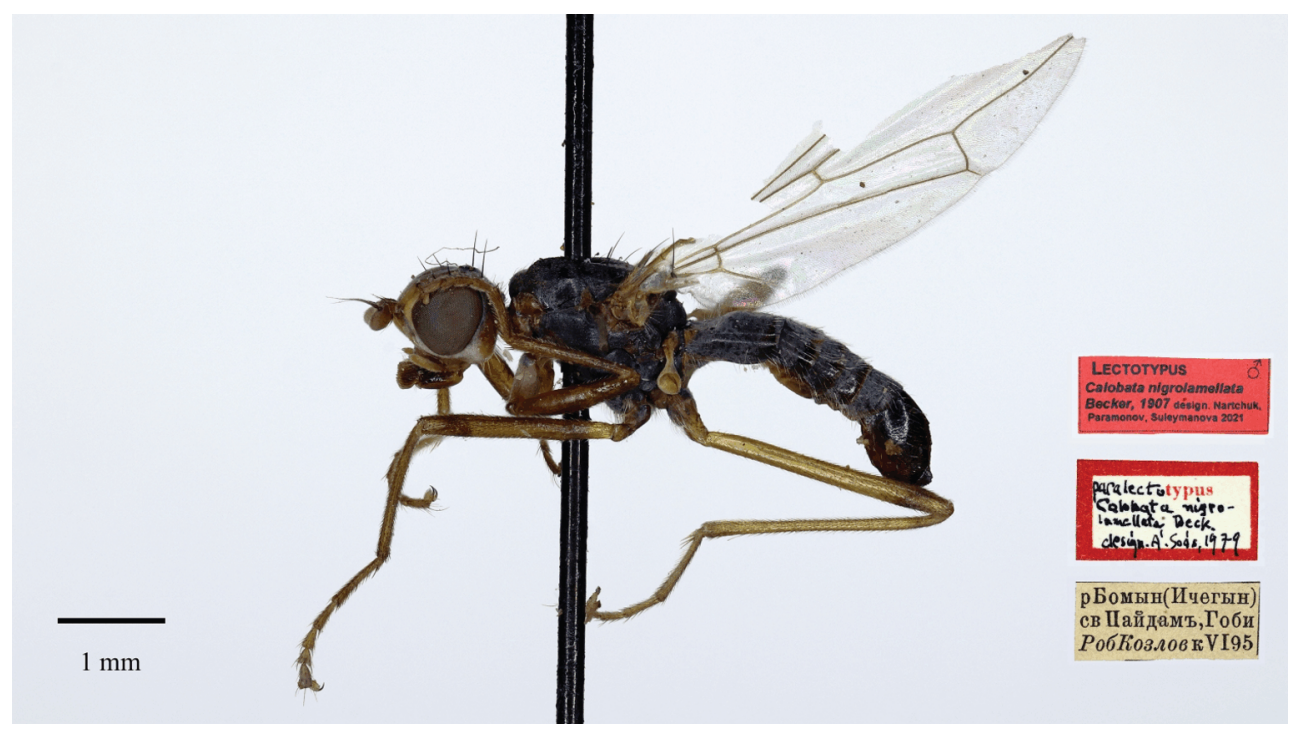

Fig. 2. Calobata nigrolamellata Becker, 1907, lectotype. Photograph by N.M. Paramonov. 
Satschou, 24-27.VI.(18)95 (Roborowski)." The type has not been found in the ZISP collection.

\section{Calobata nigrolamellata Becker, 1907}

Becker, 1907 : 294 (Fig. 2).

The species was described from 3 specimens, 2 of which were found in the ZISP collection. Lectotype, designated here, "[China]: Bomyn (Ichegyn) R. ne [northestern] Tsaidam, Gobi, [end of] VI.(18)95 (Rob. [orovskii], Kozlov)" (in Cyrillic). The inventory number is INS_DIP_0000902. This male perfectly corresponding to T. Becker's description is designated as the lectotype, since we failed to examine the specimen deposited in Berlin, which Á. Soós probably planned to designate as the lectotype: during his visit to St. Petersburg (Leningrad at that time) he supplied the specimen with his label "paralectotypus des. Soós, 1979," but there is no lectotype designation in his publications. Paralectotype: a female with a similar label. Another male with a label as that of the lectotype is deposited in the Zoological Museum in Berlin; it was donated to T. Becker when he examined the ZISP collection (Schumann, 1988 : 102).

\section{Micropeza turkestanica Ozerov, 2008}

Ozerov, $2008: 436$ (Fig. 3).

Holotype: male, "[Kazakhstan] 6 km S [of] Bakanas, Alma-Atinskaya obl[ast], Ili R. flood plain, meadow. 30.VII.(1)969 (Gorodkov)." The inventory number INS_DIP_0000903. The holotype has no abdomen. Paratypes: 1 male, "[Kazakhstan], B.[olshaya] Almatinka [River,] Semir[echie][,] priyutsk[aya] kolon[iya]. 22.VII.(19)28 (Shnitnikov);” “[China] r[iver] Danhe S of Sachzhou[,] Gashun Gobi. 2427.VII.(18)95 (Rob.[orovskii][,] Kozlov);” 1 male, 1 female, and 2 specimens without abdomen: "[China] Bomyn (Ichegyn) R. s[evernyi] [= northern] Tsaidam, Gobi k[onets] [= end of] VI.(18)95 (Rob.[orovskii][,] Kozlov)."

Other paratypes are deposited in the Zoological Museum of Moscow State University in Moscow.

The collection includes 5 specimens of flies of the family Micropezidae, identified by J.W. Meigen, from J. Waltl's collection.

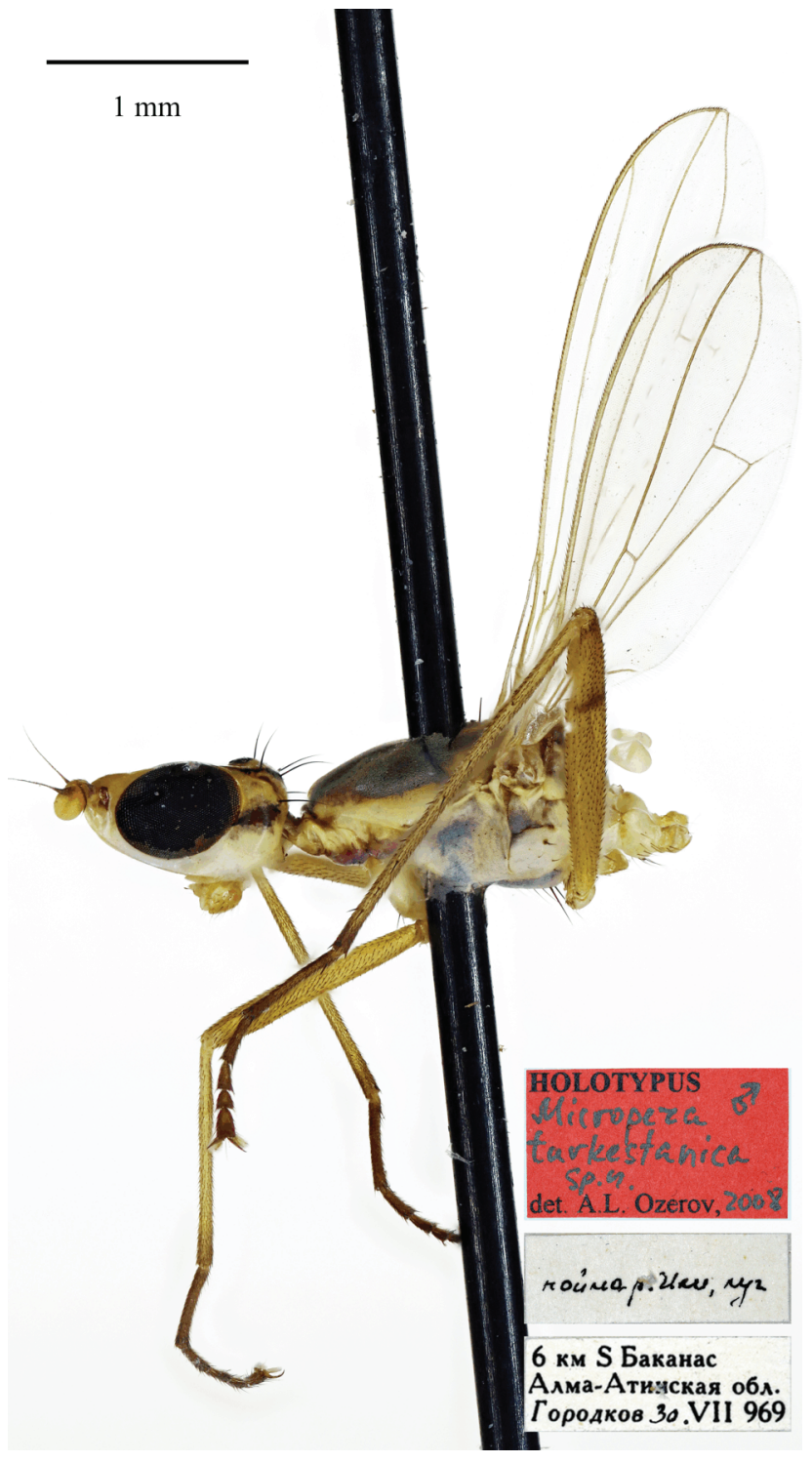

Fig. 3. Micropeza turkestanica Ozerov, 2008, holotype. Photograph by N.M. Paramonov.

Calobata petronella (Linnaeus, 1761).

Calobata cibaria $($ Linnaeus, 1761$)=$ Compsobata cibaria.

Calobata cothurnata (Bigot, 1878) = Compsobata (Trilophyrobata) nigricornis (Zetterstedt, 1838).

Micropeza corrigiolata (Linnaeus, 1767).

Micropeza lateralis Meigen, 1826.

Family TETHINIDAE Hendel, 1916

The flies are small $(1.5-3.5 \mathrm{~mm})$, with a gray body covered with dense pruinosity. The family is world-wide 


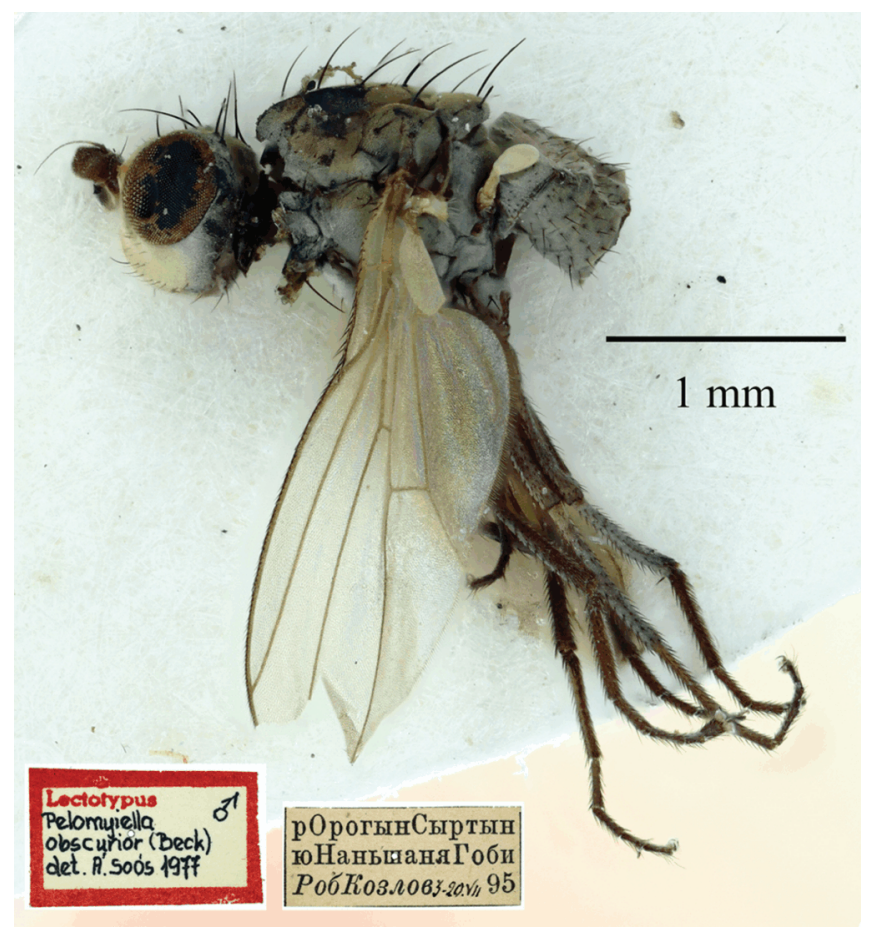

Fig. 4. Pelomyiella obscurior Becker, 1907, lectotype. Photograph by N.M. Paramonov.

distributed and comprises about 100 species. In Russia, about 20 species of 3 genera are known. The flies are halophilous; they occur on the sea shores, on dunes, near salty lakes, and in saline meadows, and also often inhabit technogenic landscapes. The mode of life of the larvae is unknown.

Pelomyiella obscurior Becker, 1907

Becker, 1907 : 308 (Fig. 4).

The species was described based on 6 specimens, 4 of which are deposited in the ZISP collection. Lectotype: male (des. Soós, 1978 : 410) "Orogyn Syrtyn R. S of Nan Shan[,] Gobi. 3-20.VII.(18)95 (Rob.[orovskii][,] Kozlov).” The inventory number is INS_DIP_0000904. Paralectotypes: 1 male and 1 female with a label as that of the holotype. In Soós's opinion (Soós, 1978), one paralectotype with the geographical label "Kurlyk, Baingol[,] vost[ochnyi = eastern] Tsaidam. 16-24.V.(18)95 (Rob.[orovskii][,] Kozlov)" belongs to Pelomyiella mallochi (Sturtevant, 1923). Two paralectotypes are deposited in the Zoological Museum of the Bulgarian Academy of Sciences in Sofia; they were

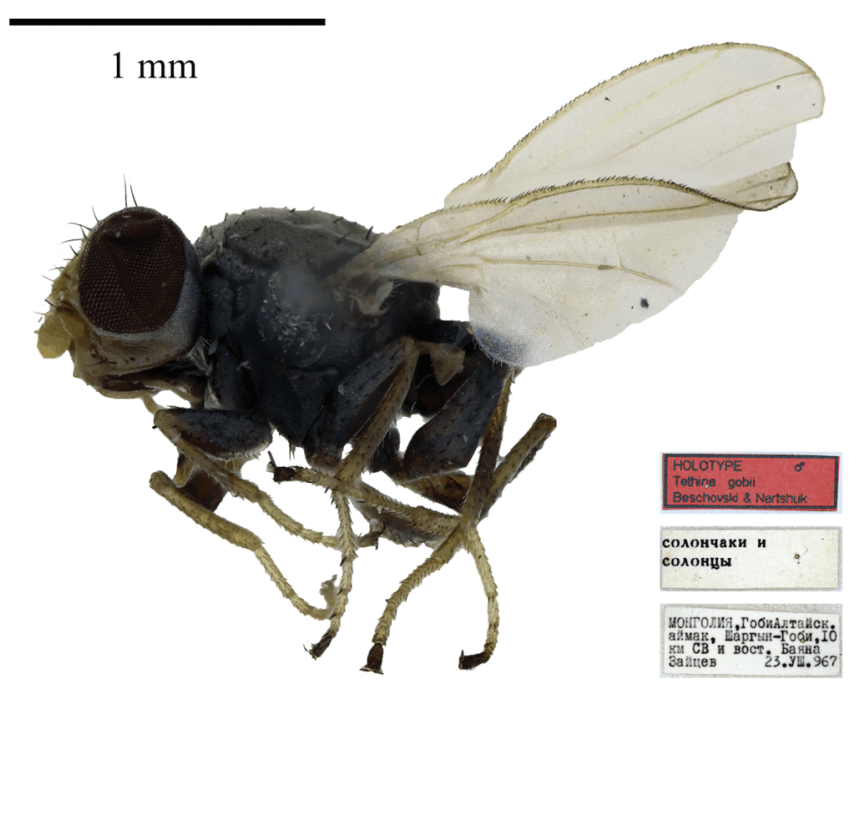

Fig. 5. Tethina gobii Beschovski et Nartshuk, 1997, holotype. Photograph by N.M. Paramonov.

donated to V. Beschovski when he examined the ZISP collection (Beschovski and Nartshuk, 1997).

Tethina gobii Beschovski et Nartshuk, 1997

Beschovski and Nartshuk, 1997 : 131 (Fig. 5).

Holotype: male, "Mongolia, Gobi[-]Altaisk[ii] aimak, Shargyn-Gobi [Desert], $10 \mathrm{~km} \mathrm{NE}$ and [east] of Bajan. 23.VIII.(1)967 solonchaks and solonets (Zaitsev)." The inventory number is INS_DIP_0000905. A microvial with the genitalia is pinned under the specimen.

Tethina luteosetosa Beschovski et Nartshuk, 1997

Beschovski and Nartshuk, 1997 : 133 (Fig. 6).

Holotype: male, "Mongolia, Bajan[-]Khongorsk[ii] aimak, 24 and $35 \mathrm{~km}$ E of Talyn-Bilgekh-Bulag [Spring]. 17.VIII.(1)969 (M. Kozlov).” The inventory number is INS_DIP_0000906. In the holotype, the abdomen is cut off, but a microvial with the genitalia is missing. Paratypes: 4 males with a label as that of the holotype; 2 males and 2 females, "[Turkmenistan] Molla-Kara 


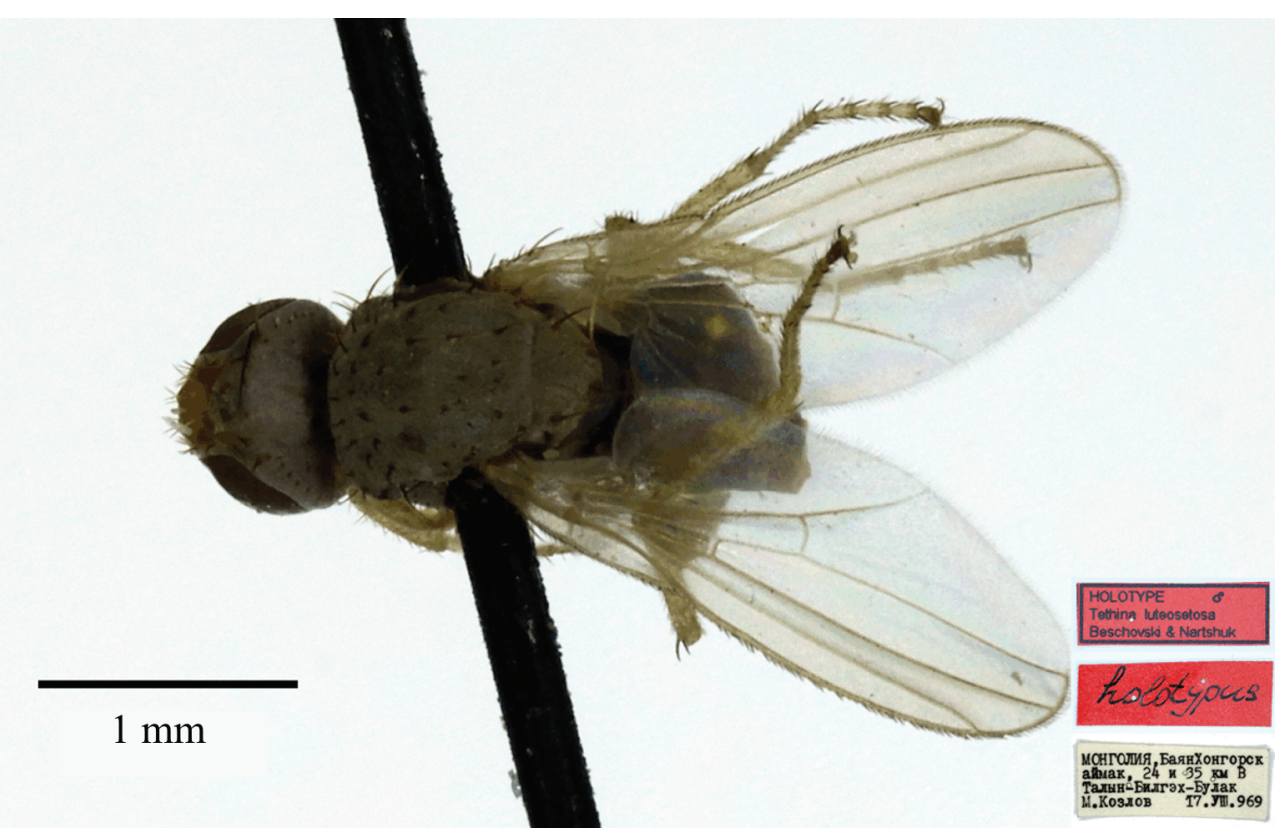

Fig. 6. Tethina luteosetosa Beschovski et Nartshuk, 1997, holotype. Photograph by N.M. Paramonov.

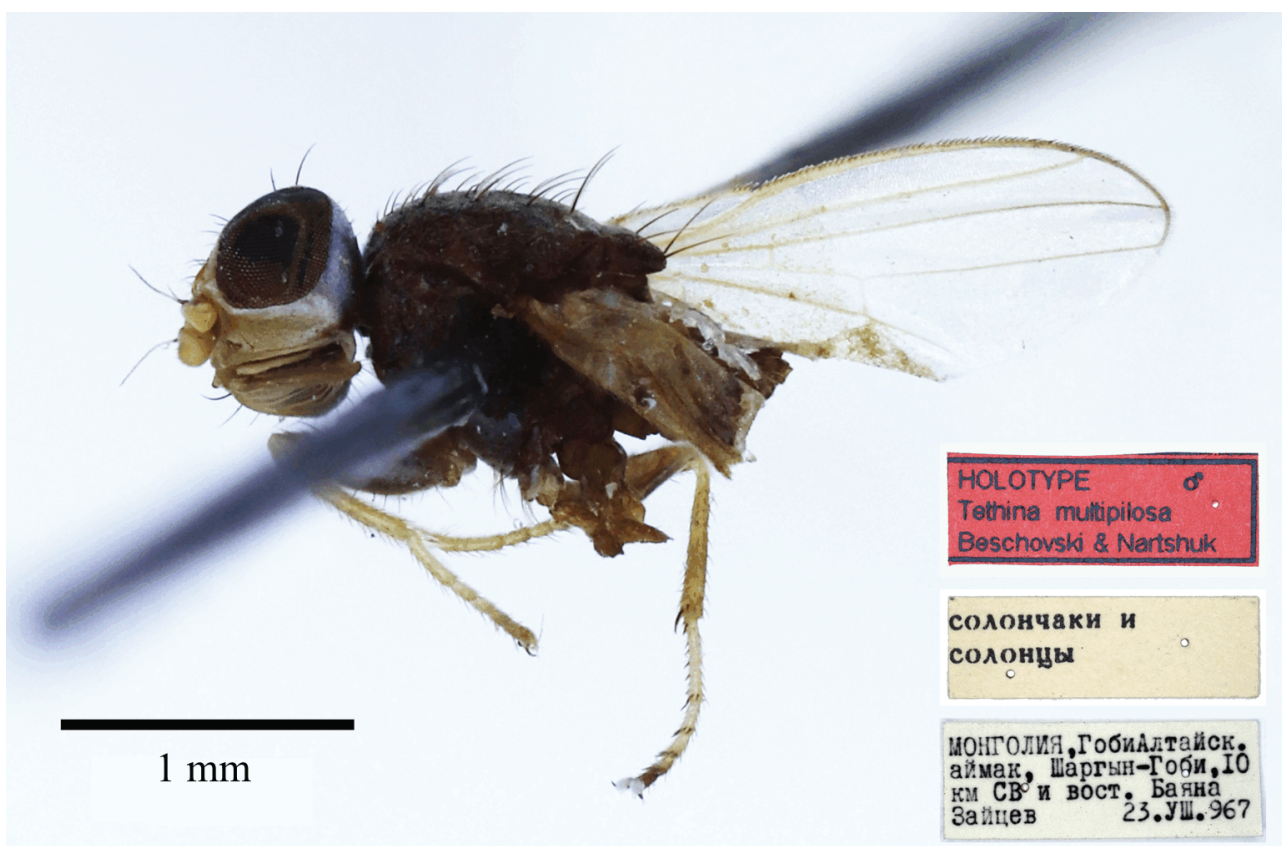

Fig. 7. Tethina multipilosa Beschovski et Nartshuk, 1997, holotype. Photograph by N.M. Paramonov. 
[near] Dzhebel, 6.VI.(1)934 (V. Popov);" 9 males (a microvial with the genitalia is pinned under one specimen) and 11 females (microvials with the genitalia are pinned under two specimens); all with the label "Molla-Kara [near] Jebel. Turkm.[enia]. 9.VI.(1)934 (V. Popov);" 21 males (microvials with the genitalia are pinned under two specimens) and 11 females (microvials with the genitalia are pinned under two specimens) with the label "Mongolia, South[-] Gobi aimak, Bordzon-Gobi[,] 80 km SSE of Nongon. 5-8.VIII.(1)967, meadow-like habitat with read and Nitre bush (Kerzhner);" 1 female, "Mongolia, Bajan[-]Khongorsk[ii] aimak, vost.[ochnyi, = eastern] shore of Lake Adgiin-Tsagan-Nur, on Tamarix, 19-20.VIII.(1)967 (Kerzhner)." The following paratypes: a male with a label as that of the holotype; 1 male and 3 females, "Turkmenia Molla-Kara [near] Jebel, 6.VI.(1)934 (V. Popov);" 1 male with the label "Mongolia, Bajan[-] Khongorsk[ii] aimak, Ongon-Ulan-Ula Mountains, pass, 11.VIII.(1)969 (Zaitsev)" and 1 female with the label "Mongolia, Bajan[-]Khongorsk[ii] aimak, Echin-Gol oasis, 11-14.VIII.(1)969 (Zaitsev)" are in the collection of the Zoological Institute of the Bulgarian Academy of Sciences in Sofia; they were donetedto V. Beschovski when he examined the ZISP collection (Beschovski and Nartshuk, 1997).

Tethina multipilosa Beschovski et Nartshuk, 1997

Beschovski and Nartshuk, 1997 : 35 (Fig. 7).

Holotype: male, "Mongolia, Gobi[-]Altaisk[ii] aimak, Shargyn-Gobi [Desert], $10 \mathrm{~km} \mathrm{NE}$ and [east] of Bajan. 23.VIII.(1)967, "solonchaks and solonets" (Zaitsev).” The inventory number is INS_DIP_0000907. A microvial with the genitalia is pinned under the specimen.

\section{FUNDING}

The study was performed based on the collection of the Zoological Institute, Russian Academy of Sciences (state project no. AAAA-A19-119020690082-8).

\section{COMPLIANCE WITH ETHICAL STANDARDS}

The authors declare that they have no conflict of interest. All the applicable international, national, and institutional guidelines for the care and use of animals were followed. All the procedures performed in studies involving animals were in accordance with the ethical standards of the institution or practice at which the studies were conducted.

\section{OPEN ACCESS}

This article is licensed under a Creative Commons Attribution 4.0 International License, which permits use, sharing, adaptation, distribution and reproduction in any medium or format, as long as you give appropriate credit to the original author(s) and the source, provide a link to the Creative Commons license, and indicate if changes were made. The images or other third party material in this article are included in the article's Creative Commons license, unless indicated otherwise in a credit line to the material. If material is not included in the article's Creative Commons license and your intended use is not permitted by statutory regulation or exceeds the permitted use, you will need to obtain permission directly from the copyright holder. To view a copy of this license, visit http://creativecommons.org/licenses/by/4.0/.

\section{REFERENCES}

Becker, T., Zur Kenntnis der Dipteren von Zentral Asien. I. Cyclorrhapha Schizophora, Holometopa und Orthorrhapha / Brachycera, Ezhegodnik Zoologicheskogo Muzeya Imperatorskoi Akademii Nauk, 1907, vol. 12, no. 3, p. 293.

Beschovski, V.L. and Nartshuk, E.P., The Tethinidae species in the collection of the Zoological Institute in St. Petersburg (Insecta: Diptera: Tethinidae), Reichenbachia, 1997, vol. 32, no. 22, p. 129.

Ozerov, A.L., Flies of the genus Micropeza Meigen (Diptera, Micropezidae) of the Russian fauna, Russ. Entomol. J., 2008, vol. 17, no. 4, p. 429.

Schumann, H., Die Micropeziden-Typen der Dipteren-Sammlung des Zoologischen Museums in Berlin, Mitt. Zool. Mus. Berl., 1988, vol. 64, no. 1, p. 83.

Shatalkin, A.I., Palaearctic species of Pseudopomyzidae (Diptera), Russ. Entomol. J., 1994, vol. 3, nos. 3-4, p. 129.

Soós, Á., Tethiniden aus der Mongolei mit einem Verzeichnis der paläarktischen Arten (Diptera: Acalyptratae), Acta Zool. Acad. Sci. Hung., 1978, vol. 24, nos. 3-4, p. 407. 